\title{
An audit of preschool vision screening
}

\author{
John W Allen, Bratati Bose
}

\begin{abstract}
An audit was carried out to clarify the dispute surrounding the vision screening test at 3.5 years. The uptake was $53 \cdot 5 \%$, sensitivity $77 \%$, specificity $96 \%$, and positive predictive value $50 \%$. In particular the uptake was poor and the test needed a clear policy for the future.
\end{abstract}

(Arch Dis Child 1992;67:1292-3)

The vision screening test at 3.5 years of age aims to find 'cases' of reduced visual acuity, amblyopia, and squint. Opinion is divided about its value, ${ }^{1-5}$ and a recent report on child health surveillance recommended that it should be discontinued. ${ }^{3}$ This debate together with the emerging role of the community orthopist prompted an audit to find out 'what was happening' and 'what should be done'. The performance of the test was evaluated by measuring its uptake, sensitivity, specificity, and positive predictive value. ${ }^{6}$

\section{Subjects and methods}

The target population was 1365 primary schoolchildren in Lancaster born between 1981 and 1983. A random sample of 599 school health records provided the data. Special schools were not included.

The test of visual acuity in school entrants was used as the reference test and was recorded in 531 children, which formed the eligible population for this study. A positive case was defined as a visual acuity of $6 / 12$ or worse in either eye and squint was excluded. The 531 records were inspected and the validity of the screening test result classified according to the outcome of the reference test. ${ }^{6}$ Records of false positives were checked to take account of the possible effects of any treatment on classification.

The vision screening at 3.5 years was carried out by clinical medical officers using the Stycar vision test with five single letter matching at 3 metres (mean age 3.5 years). The reference test was carried out by school nurses using the Stycar vision test with seven single letter matching at 6 metres (mean age $5 \cdot 1$ years).

Results

At 5 years the prevalence of reduced visual

Table 1 Uptake of the vision screening test at 3.5 years $(n=531)$. Results are number (\%)

\begin{tabular}{llllll}
\hline $\begin{array}{l}\text { Missing } \\
\text { preschool records }\end{array}$ & $\begin{array}{l}\text { No } \\
\text { recording }\end{array}$ & $\begin{array}{l}\text { Did not } \\
\text { attend }\end{array}$ & $\begin{array}{l}\text { Did not } \\
\text { cooperate }\end{array}$ & Uptake & Total \\
\hline $39(7 \cdot 3)$ & $93(17 \cdot 5)$ & $63(11 \cdot 9)$ & $52(9 \cdot 8)$ & $284(53 \cdot 5)$ & $531(100)$ \\
\hline
\end{tabular}

Table 2 A comparison of the reference test to the outcome of the screening test $(n=284)$

\begin{tabular}{llll}
\hline & \multicolumn{2}{l}{ Reference test } & \\
\cline { 2 - 4 } & Positive & Negative & Total \\
\hline $\begin{array}{l}\text { Screening test: } \\
\text { Positive }\end{array}$ & 10 & 10 & 20 \\
Negative. & 3 & 261 & 264 \\
Total & 13 & 271 & 284 \\
\hline
\end{tabular}

acuity in either eye was $6 / 12$ or worse in $4.5 \%$ $(24 / 531)$ and $6 / 18$ or worse in $2 \cdot 1 \%(11 / 531)$.

Table 1 shows the uptake of the screening test. In the $63.3 \%(336 / 531)$ who attended, $84.5 \%(284 / 336)$ cooperated. The largest single group $(17.5 \%)$ with no test at 3.5 years had no evident recording in the notes and $49 \%$ in this group were children who had transferred into Lancaster.

Table 2 shows the results of comparing the reference test to the outcome of the screening test. The sensitivity was $77 \%(10 / 13)$, specificity $96 \%(261 / 271)$, and positive predictive value $50 \%(10 / 20)$.

In the $\mathbf{1 0}$ false positive cases (table 2) that were followed up for the possible effects of treatment, nine received no treatment and one was lost to follow up.

\section{Discussion}

An audit should compare results with standards but in their absence comparisons were largely confined to peers: orthoptists, ${ }^{124}$ health visitors, ${ }^{2}$ trained nurses, ${ }^{5}$ and a paediatrician. ${ }^{5}$ All these authors included squint in their studies.

The attendance of $63 \%$ was poor when compared with $95 \%{ }^{5}$ and $70-75 \%{ }^{4}$ but was akin to $67 \%{ }^{1}$ and a coverage of $60 \%$ (orthoptists) and $59-84 \%$ (health visitors). ${ }^{2}$ The cooperation of $84.5 \%$ was also poor and other authors report $95 \%{ }^{4}$ and $98 \% .^{5}$. The final uptake of $53.5 \%$ in this study was low compared with a reported $93 \%{ }^{5}$ and $63 \% .^{4}$

Some explanation should be offered for the poor results shown in table 1 . The absence of records and poor record keeping of the vision test at 3.5 years highlights some of the administrative difficulties in record keeping in the community. There was a large group with no recording of the test at this age, however $49 \%$ of this group had transferred into the district. There is, however, little excuse for the lax recording in the remaining $51 \%$. It is unlikely that incorrect addresses were a significant cause of failure to attend as these were checked before the appointment. Neither can failure to attend 
be attributed wholly to poor socioeconomic factors as Lancaster is a rural district with a good vaccination uptake. It is likely that the assessment was unpopular or unacceptable to clients.

In the screened population the sensitivity of $77 \%$ compares with results achieved by others: $90 \%^{1}$ and $100 \%$ (orthoptists) and $43 \%$ (health visitors). ${ }^{2}$ The high specificity of $96 \%$ was similar to $99 \%^{1}$ and $98-100 \% .^{2}$ A positive predictive value of $50 \%$ indicates excessive over referrals and compares poorly with others who have obtained $94 \%{ }^{1}$ and $74 \%$ (orthoptists) and $100 \%$ (health visitors). ${ }^{2}$ False positives are a hazard of screening causing unnecessary work for staff and concern to clients.

The study can be criticised for the length of time between the screening and the reference test. Amblyopia might have developed and an improvement might have occurred under possible treatment in the one case that could not be followed up. We do not, however, consider that the values of performance would have been significantly affected. Furthermore a more extensive study would have included squint and an ophthalmological opinion. Nevertheless the work was revealing enough when confined to visual acuity. When considering 'what should be done' any decision should be based on the standard prerequisites for screening. ${ }^{7}$

The test was largely unacceptable with a poor sensitivity and positive predictive value. There was no evidence of a controlled study showing effective treatment for amblyopia. Clearly the prerequisites for a screening programme were not met and the test in Lancaster was manifestly unsatisfactory. However, it is easier to refrain from embarking on a programme than to dismantle an existing one that has public expectations.

The developmental assessment at 3.5 years together with the vision screening test has been transferred to health visitors and high standards of ongoing training are a clear necessity. A poor uptake was a significant problem and as health visitors work on a domicillary basis an increased uptake can be expected.

The cycle of audit in this study requires completion and there is a need for a controlled trial demonstrating the effective treatment of amblyopia. The wealth of paperwork in the community health services is fertile ground for further work in audit.

We are indebted to Joanne Huntington for her patience and skill with the typing and Mariët for her support.

1 Wormald RPL. Preschool vision screening in Cornwall: performance indicators of community orthoptists. Arch D Child 1991;66:917-20.

2 Jarvis SN, Tamhne RC, Thompson L, Francis PM Anderson J, Colver AF. Preschool vision screening. Arch Dis Child 1990;65:288-94.

3 Hall DMB, ed. Health for all children. Oxford: Oxford University Press, 1989.

4 Ingram RM, Holland WW, Walker C, Wilson JM, Arnold PE, Dally S. Screening for visual defects in preschool children. Brf Ophthalmol 1986;70:16-21.

5 Köldr L. Stigmar G. Vision screening of four year old children. Acta Paediatr Scand 1973;62:17-27.

6 Rose G, Barker DJP. Epidemiology for the uninitiated: Rose G, Barker DJP. Epidemio

7 Wilson JMG, Junger G. Principles and practices of screening for disease. WHO: Geneva, 1968. Public Health Paper No 34. 